\title{
Overview of DaxibotulinumtoxinA for Injection: A Novel Formulation of Botulinum Toxin Type A
}

\author{
Nowell Solish $^{1} \cdot$ Jean Carruthers ${ }^{2} \cdot$ Joely Kaufman ${ }^{3} \cdot$ Roman G. Rubio $^{4} \cdot$ Todd M. Gross $^{4} \cdot$ Conor J. Gallagher $^{4}$
}

Accepted: 13 October 2021 / Published online: 17 November 2021

(c) The Author(s) 2021

\begin{abstract}
Botulinum toxin type A (BoNTA) products are widely used for therapeutic and aesthetic indications, but there is a need for longer-lasting treatments that maintain symptom relief between injections and reduce the frequency of re-treatment. DaxibotulinumtoxinA for Injection (DAXI) is a novel BoNTA product containing highly purified 150-kDa core neurotoxin and is the first to be formulated with a proprietary stabilizing excipient peptide (RTP004) instead of human serum albumin. The positively charged RTP004 has been shown to enhance binding of the neurotoxin to neuronal surfaces, which may enhance the likelihood of neurotoxin internalization. DAXI produces robust, extended efficacy across both aesthetic and therapeutic indications. In an extensive glabellar lines clinical program, DAXI showed a high degree of efficacy, a consistent median time to loss of none or mild glabellar line severity of 24 weeks, and median time until return to baseline of up to 28 weeks. In adults with cervical dystonia, DAXI at $125 \mathrm{U}$ and $250 \mathrm{U}$ significantly improved Toronto Western Spasmodic Torticollis Rating Scale (TWSTRS) total scores, with a median duration of efficacy of 24 and 20 weeks, respectively, which compares favorably with the 12-14 weeks' duration reported for approved BoNTA products. Overall, DAXI was well tolerated, and the consistent extended duration of effect suggests that DAXI has the potential to improve the management of both aesthetic and therapeutic conditions.
\end{abstract}

\section{Plain Language Summary}

Botulinum toxin is used to block the nerve signals that cause muscles to contract. Products containing botulinum toxin are commonly given by injection to treat muscle spasms (such as cervical dystonia, a painful condition where the neck muscles contract involuntarily) and for cosmetic treatment of frown lines. However, the effects of the currently approved botulinum toxin products typically wear off about 3-4 months after injection and so the injections must be repeated regularly. A new product called DAXI (DaxibotulinumtoxinA for Injection) has been developed. In this product, the botulinum toxin is formulated with a unique protein (called RTP004) that has been designed to help deliver the botulinum toxin to the nerve cells. Research suggests that the RTP004 protein in DAXI adheres the botulinum toxin to the nerves close to the injection site, potentially making its effect last longer. To date, DAXI has been studied in over 3800 patients. The studies have shown that DAXI is effective for treating neck spasms (cervical dystonia) and for reducing the appearance of frown lines. Importantly, the effects of DAXI lasted up to 6 months, which is longer than seen with other botulinum toxin products. The side effects seen with DAXI are consistent in nature and frequency with those seen with other botulinum toxin products. These findings suggest that DAXI can improve both medical and cosmetic treatments due to its longer-lasting effect.

Conor J. Gallagher

cgallagher@revance.com

1 University of Toronto, Toronto, Canada

2 University of British Columbia and Jean Carruthers Cosmetic, Vancouver, BC, Canada

3 Skin Associates of South Florida, Coral Gables, FL, USA

4 Revance Therapeutics, Inc., 7555 Gateway Boulevard, Newark, CA 94560, USA

\section{Introduction}

Over the past several decades, a large volume of clinical data has demonstrated the efficacy and safety of botulinum toxin type A (BoNTA) products for treating medical conditions, such as cervical dystonia, upper limb spasticity, chronic migraine headaches, overactive bladder, and blepharospasm, as well as aesthetic concerns, such as facial lines [1-3]. 


\section{Key Points}

Longer-lasting botulinum toxin type A (BoNTA) products are needed for therapeutic and aesthetic indications to maintain stable clinical effects between injections and potentially reduce the frequency of re-treatment.

DaxibotulinumtoxinA for Injection (DAXI) is a novel BoNTA utilizing a proprietary stabilizing excipient peptide (RTP004) in place of human serum albumin.

DAXI has consistently demonstrated a median effect duration of 24 weeks in the treatment of cervical dystonia and glabellar lines, suggesting that DAXI has the potential to improve the management of both aesthetic and therapeutic conditions.

Despite the widespread use of BoNTAs for therapeutic and aesthetic indications, a limitation of all currently available BoNTA products is their duration of effect. Most BoNTAs currently approved in the USA have a recommended re-treatment interval of 12-16 weeks (3-4 months) [4-7]. In cervical dystonia, however, patients have reported declines in symptom relief after a mean of 9.5 weeks [8], re-emergence of cervical dystonia symptoms between injections [9, 10], and low satisfaction with BoNTA treatment prior to reinjection [8], with many saying they would like a longer-lasting BoNTA treatment and more stable symptom relief $[9,10]$. Product labelling prohibits re-treatment intervals shorter than 12 weeks $[4,5,7]$ and health insurance will typically not reimburse for more frequent treatments. As a result, patients may face a period of inadequate symptom relief.

Similar evidence suggests that patients treated for glabellar lines desire longer-lasting effects. The reported duration of effect on glabellar lines for currently approved BoNTA products is approximately 3-4 months [5-7], such that patients require 3 or 4 treatments annually to maintain the clinical benefit. In 2018, an online survey found that $88 \%$ of respondents (among 1004 women aged 25-70 years who had used a neuromodulator in the last 5 years) indicated a BoNTA product offering long-lasting aesthetic results was absolutely essential or very important when considering a neuromodulator [11]. Further, while reimbursement decisions do not drive re-treatment timing in aesthetic indications, patients often limit themselves to twice yearly treatments [11], resulting in periods of suboptimal correction.

To date, none of the currently available BoNTA products has consistently demonstrated a clinically distinct peak efficacy (response rate), duration of therapeutic benefit, or safety profile. DaxibotulinumtoxinA for Injection (DAXI; Revance Therapeutics, Inc., Newark, CA) is a novel BoNTA product, containing purified $150-\mathrm{kDa}$ core neurotoxin and a proprietary excipient peptide, and is in clinical development for multiple therapeutic (cervical dystonia and upper limb spasticity) [12-14] and aesthetic indications (upper facial lines including glabellar lines, forehead lines, and lateral canthal lines) [15-17]. The formulation of DAXI and the clinical data from the extensive development program establish its role as a novel BoNTA with potential to improve upon the efficacy and safety of currently approved BoNTAs. This article describes the unique product characteristics and manufacturing of DAXI and summarizes the currently available DAXI clinical data.

\section{Background on DAXI}

\subsection{Product Characteristics}

The neurotoxin in DAXI and all other BoNTA products is derived from the Hall strain of Clostridium botulinum [18]; however, DAXI is the only BoNTA product that is wholly manufactured and formulated in the USA. The formulation consists of highly purified daxibotulinumtoxinA (RTT150, a $150-\mathrm{kDa}$ BoNTA), a stabilizing peptide that binds the neurotoxin with high avidity, and other excipients, including polysorbate-20 (a surfactant), buffers, and a sugar [15]. Whereas all other BoNT products rely on human serum albumin (HSA) as an excipient to limit the aggregation of BoNT molecules and their adsorption to glass surfaces [19], the unique formulation of DAXI, combining the novel, proprietary stabilizing excipient peptide (RTP004) along with polysorbate-20, allows for an HSA-free product [20] (summarized in Table 1).

RTP004 is a 35-amino acid peptide that is highly positively charged at physiologic $\mathrm{pH}$ and forms a strong electrostatic bond with daxibotulinumtoxinA. RTP004 is wholly synthetic and is constructed with two distinct domains: a core domain of 15 consecutive lysines that is flanked at each terminus by a 10 -amino acid protein transduction domain (PTD). The cationic, arginine-rich PTD in RTP004 was originally identified as a region between residues 48-60 of the 86-amino acid transcriptional activator (TAT) coded for by HIV-1, a sequence that permitted transduction of proteins across cell membranes [21]. TAT-PTD complexes are thought to enter cells by endocytosis [22] and are in development for the intracellular delivery of therapeutic proteins for conditions such as central nervous system disorders, eye diseases, diabetes, and several types of cancer [23-26]. The RTP004 structure, with a PTD at each terminus, makes DAXI unlike other PTD-containing products in development that typically comprise a single PTD conjugated to the protein of interest.

The strong net positive charge of RTP004 drives electrostatic binding to negatively charged extracellular structures, 
Table 1 Botulinum toxin type A products for aesthetic indications in the USA: summary of product characteristics

\begin{tabular}{|c|c|c|c|c|c|}
\hline & DaxibotulinumtoxinA & $\begin{array}{l}\text { OnabotulinumtoxinA } \\
{[4,6]}\end{array}$ & $\begin{array}{l}\text { AbobotulinumtoxinA } \\
\text { [5] }\end{array}$ & $\begin{array}{l}\text { IncobotulinumtoxinA } \\
\text { [7] }\end{array}$ & $\begin{array}{l}\text { PrabotulinumtoxinA } \\
\text { [36] }\end{array}$ \\
\hline Molecular weight (kDa) & 150 & 900 & $\sim 400$ & 150 & 900 \\
\hline $\begin{array}{l}\text { Contains accessory } \\
\text { proteins }\end{array}$ & No & Yes & Yes & No & Yes \\
\hline Contains HSA & No & Yes; $500 \mu \mathrm{g}$ & Yes; $125 \mu \mathrm{g}$ & Yes; $1 \mathrm{mg}$ & Yes \\
\hline Excipients & $\begin{array}{l}\text { PS20, sugar, buffer, } \\
\text { excipient peptide } \\
\text { (RTP004) }\end{array}$ & $\begin{array}{l}\text { Sodium chloride, } \\
\text { HSA }\end{array}$ & Lactose, HSA & Sucrose, HSA & Sodium chloride, HSA \\
\hline Stabilization & Lyophilization & Vacuum drying & Lyophilization & Lyophilization & Vacuum drying \\
\hline Solubilization & Normal saline & Normal saline & Normal saline & Normal saline & Normal saline \\
\hline $\begin{array}{l}\text { Shelf-life once reconsti- } \\
\text { tuted }(\mathrm{h})\end{array}$ & 72 & 36 & 24 & 36 & 24 \\
\hline $\begin{array}{l}\text { Can be stored at room } \\
\text { temperature unrecon- } \\
\text { stituted }\end{array}$ & Yes & No & No & Yes & No \\
\hline Purification method & Chromatography & Crystallization & Chromatography & NA & NA \\
\hline $\begin{array}{l}100 \% \text { sourced and } \\
\text { manufactured in USA }\end{array}$ & Yes & No & No & No & No \\
\hline Glabellar line dose $(\mathrm{U})$ & 40 & 20 & 50 & 20 & 20 \\
\hline $\begin{array}{l}\text { Mass of core neurotoxin } \\
\text { in glabellar line dose } \\
\text { (ng) }[36,53]\end{array}$ & 0.18 & 0.18 & 0.27 & 0.08 & 0.12 \\
\hline $\begin{array}{l}\text { Glabellar line response } \\
\text { rate }(\geq 2 \text {-point } \\
\text { improvement from } \\
\text { baseline based on } \\
\text { investigator and sub- } \\
\text { ject assessment) }(\%)\end{array}$ & 74 & NA & $52-60$ & $48-60$ & $67-71$ \\
\hline $\begin{array}{l}\text { Median duration of } \\
\text { effect }\end{array}$ & 24 weeks/ 6 months & 3-4 months & Up to 4 months & Up to 3 months & $\begin{array}{l}\text { Only } 1 \text {-month data } \\
\text { reported }\end{array}$ \\
\hline
\end{tabular}

HSA human serum albumin, NA not applicable, PS20 polysorbate-20

such as neuronal surfaces and extracellular matrix proteins. Specifically, in vitro surface plasmon resonance, a sensor of biomolecular interactions used to measure the kinetics of binding/dissociation, has demonstrated that RTP004 increases binding of DAXI to a lipid membrane preparation [11]. Similarly, results from an in vitro binding study with synaptosomes indicate that RTP004 increased maximal percentage binding of BoNTA heavy chain to rat brain nerve terminals [27]. Enhanced binding to nerve terminals and extracellular matrix elements may facilitate the localization of BoNTA and reduce diffusion from the injection site [28], a finding that was observed in a study of DAXI and onabotulinumtoxinA in mice [18]. In that study, a DAXI dose of 2.5 times that of the onabotulinumtoxinA dose was required to see comparable diffusion. When comparing diffusion-matched doses of the two BoNTA products, it was observed that DAXI had an extended duration of drug effect (100-126\% increase) versus onabotulinumtoxinA [18]. The strong positive charge on the peptide has been demonstrated to drive an association between the peptide and the neurotoxin, and between the peptide-toxin complex and the negatively charged presynaptic nerve terminal. The stronger binding to the nerve terminal will increase the duration of the anchoring of BoNTA at the presynaptic terminal in comparison with a neurotoxin formulation without peptide. We hypothesize that this prolonged binding will increase the likelihood of DAXI encountering its protein receptor, SV2 (synaptic vesicle glycoprotein 2), over time and thereby increase the number of BoNT molecules internalized in comparison with "non-sticky" BoNTs that may be washed away shortly after injection (Fig. 1). Pharmacologically, a greater amount of available botulinum toxin light chain inside the neuron will correlate with the longer duration of effect observed clinically with DAXI and discussed below.

Cationic amino acids (arginine and lysine), such as those in the PTD of RTP004, protect against thermally induced aggregation of protein therapeutics. At physiological $\mathrm{pH}$, the highly positively charged RTP004 peptide forms a noncovalent electrostatic interaction with anionic surfaces of the core 150-kDa neurotoxin [29]. These electrostatic interactions 
with RTP004 likely shield the core neurotoxin from selfaggregating, allowing DAXI to be formulated without the excipient HSA found in all other BoNT products [19]. In contrast, there is evidence to suggest that the presence of HSA slightly destabilizes DAXI with respect to thermally induced aggregation [20]. The DAXI formulation permits the product to be stable as a lyophilized product at room temperature for up to 3 years before reconstitution [11]. Once reconstituted with normal saline, DAXI is stable for at least $72 \mathrm{~h}$ at $2-8{ }^{\circ} \mathrm{C}$, which is considerably longer than the 24-36 $\mathrm{h}$ reported for other BoNTA products (Table 1).

RTP004 prevents adsorption of DAXI to container surfaces during manufacturing and also prevents adsorption of the core neurotoxin to the vial (likely by blocking the neurotoxin from interacting with hydrophobic areas on container surfaces) [30]. Specifically, the addition of RTP004 or polysorbate-20 alone reduces DAXI adsorption, but the combination of RTP004 and polysorbate-20 at levels present in DAXI achieve complete protection against surface adsorption [30].

\subsection{Manufacturing}

DAXI is manufactured using a complex process of fermentation, purification, and formulation. After fermentation, DAXI is purified via a tightly controlled process that includes three column chromatography steps: hydrophobic interaction chromatography, anion exchange chromatography, and cation exchange chromatography. This process removes bacterial impurities and non-toxin accessory proteins and concentrates the final product, yielding the highly purified $150-\mathrm{kDa}$ core neurotoxin. Following formulation with the peptide and other excipients, the final drug product is dried by lyophilization, forming an even cake at the bottom of the vial.

\section{DAXI Clinical Evidence}

DAXI has been administered to 3824 subjects receiving treatment within 17 clinical studies for seven clinical indications (glabellar lines, forehead lines, lateral canthal lines, upper facial lines, cervical dystonia, upper limb spasticity, and plantar fasciitis). This section summarizes results from the two Phase 3 clinical programs: glabellar lines and cervical dystonia. Of note, these two indications represent the earliest and largest applications of conventional BoNTAs.

\subsection{Overview of DAXI Glabellar Lines Clinical Program}

The glabellar lines clinical program included a Phase $1 / 2$ dose-escalation study [31], a Phase 2 dose-ranging study (which also compared DAXI to onabotulinumtoxinA $20 \mathrm{U}$ [32]), and three Phase 3 studies (two pivotal trials [15, 33]

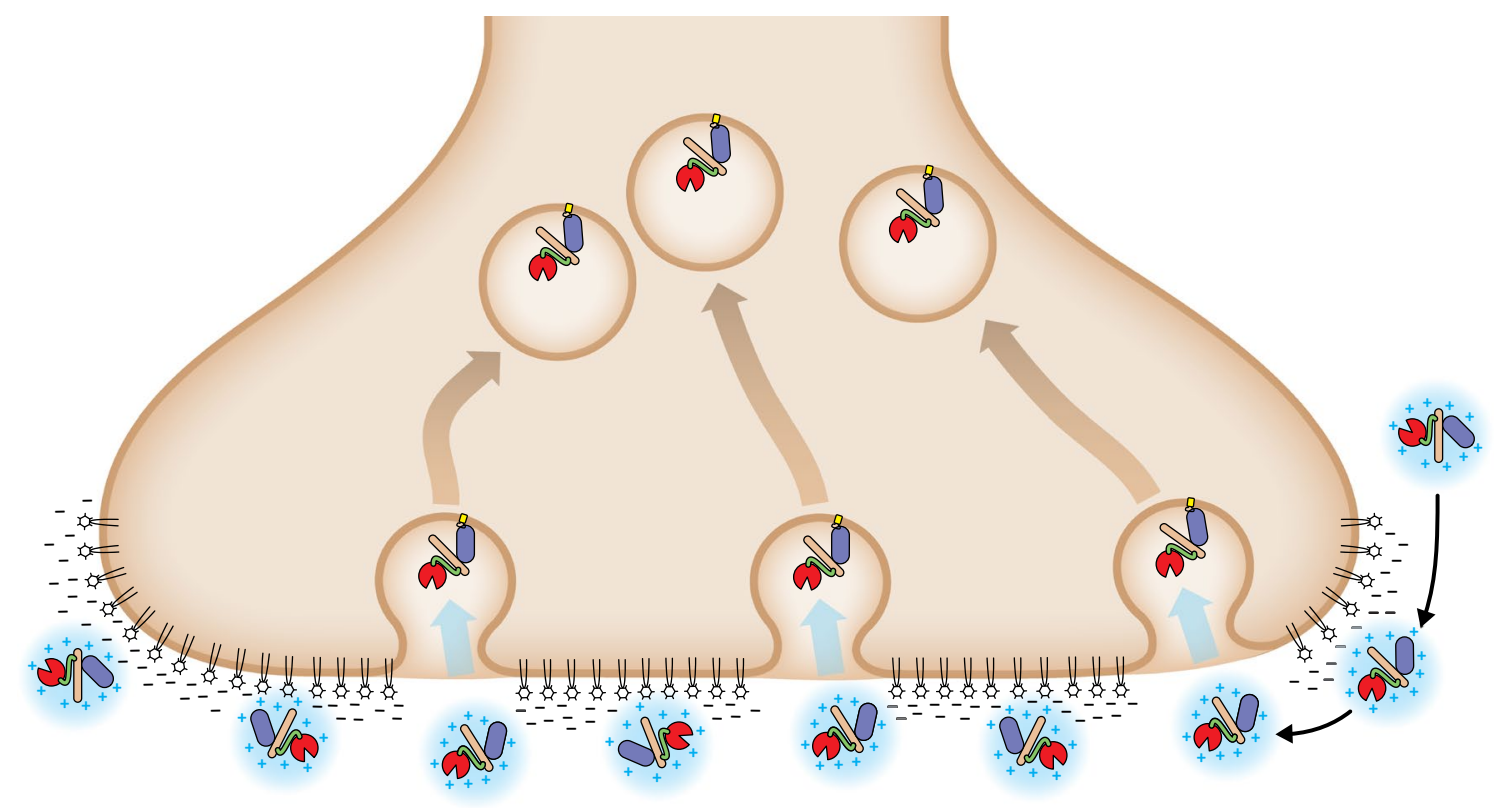

Fig. 1 Proposed mechanism of enhanced DAXI binding and internalization. In vitro data suggest that RTP004, the positively-charged stabilizing excipient peptide in the DAXI formulation, increases the affinity of the daxibotulinumtoxinA for neuronal membranes, which enhances localization of DAXI at the presynaptic terminal and may, therefore, facilitate increased internalization of the botulinum toxin molecule. = DAXI/peptide complex 
and an open-label safety study [16, 34]; Table 2). A total of 3139 adults participated in this development program, with 2994 subjects receiving 4444 DAXI treatments (at any dose). The DAXI Phase 3 clinical program in glabellar lines was the largest to date in aesthetics. Overall, the results demonstrate that DAXI is a well-tolerated treatment, offering a high degree of efficacy and up to 28 weeks' duration to return to baseline following a single treatment across the Phase 2 and 3 studies [15, 16, 33, 34], as well as durable efficacy following repeated DAXI treatment [16]. A remarkable degree of consistency in the response rates and duration profile was observed between studies and between treatment cycles in the repeat-dose, open label study.

\subsubsection{Phase 1/2 Dose-Escalation Study}

The Phase $1 / 2$ clinical study was designed to evaluate the safety of escalating doses of DAXI for the treatment of moderate-to-severe glabellar lines [31]. In total, 48 subjects were randomized to four cohorts for escalating doses of DAXI. DAXI was well tolerated and highly effective based on ratings taken at maximum frown at Week 4 and, overall, $60 \%$ of subjects had wrinkle severity of none or mild at 6 months [32]. This study indicated that DAXI may provide a benefit of extended duration and lead to the continued clinical development of DAXI.

\subsubsection{Phase 2 Dose-Ranging Study}

The randomized, double-blind, placebo-controlled, Phase

2 'Belmont' study was designed to evaluate DAXI for the treatment of glabellar lines compared to the approved dose of onabotulinumtoxin A (20 U) and placebo [32, 35]. A total of 268 adults with moderate or severe glabellar lines at maximum frown were enrolled and randomly assigned (with equal allocation) to DAXI $20 \mathrm{U}$, DAXI $40 \mathrm{U}$, DAXI $60 \mathrm{U}$, onabotulinumtoxinA $20 \mathrm{U}$, or placebo. All subjects received a single treatment and were followed for up to 24 weeks.

At Weeks 4 and 24, compared with placebo, all doses of DAXI resulted in a significantly greater proportion of subjects achieving a $\geq 1$-point improvement from baseline in glabellar line severity at maximum frown based on the fourpoint Investigator Global Assessment-Frown Wrinkle Severity (IGA-FWS) scale (Week 4: 100\% for all DAXI doses vs $3 \%$ for placebo; Week $24: 18 \%, 36 \%$, and $29 \%$ for DAXI $20 \mathrm{U}$, $40 \mathrm{U}$, and $60 \mathrm{U}$, respectively, vs $3 \%$ for placebo; $p<0.05$ for all) $[32,35]$. DAXI $40 \mathrm{U}$ also demonstrated significantly greater efficacy compared with onabotulinumtoxinA $20 \mathrm{U}$; at Weeks 16 and 24, significantly greater proportions of subjects treated with DAXI $40 \mathrm{U}$ achieved a rating of none or mild on the IGA-FWS score (Week 16: 66.7\%; Week 24: 30.8\%) versus subjects treated with onabotulinumtoxinA $20 \mathrm{U}$ (Week 16: 31.7\%; Week 24: 11.9\%; $p<0.05$ for both) [32]. Furthermore, the median duration of effect (time to loss of $\mathrm{a} \geq 1$-point improvement from baseline on IGA-FWS score) was significantly longer with DAXI $40 \mathrm{U}$ than with onabotulinumtoxinA $20 \mathrm{U}(p=0.03)$ [32].

Safety and tolerability were similar across the DAXI doses and when compared with onabotulinumtoxinA $20 \mathrm{U}$ $[32,35]$. No serious adverse events (AEs) occurred. Most AEs were predominantly localized to the injection site, transient, and mild in severity. Eyelid ptosis occurred in four

Table 2 Summary of the DAXI clinical program for the treatment of glabellar lines

\begin{tabular}{|c|c|c|c|c|c|}
\hline & Study design & Sites & Treatment & $\begin{array}{l}\text { Follow- } \\
\text { up period } \\
\text { (weeks) }\end{array}$ & $N$ \\
\hline Phase $1 / 2$ [31] & $\begin{array}{l}\text { Randomized, open-label, uncontrolled, dose-esca- } \\
\text { lation, single-center }\end{array}$ & 1 in Mexico & $\begin{array}{l}\text { DAXI } \sim 25 \mathrm{U} \\
\text { DAXI } \sim 50 \mathrm{U} \\
\text { DAXI } \sim 75 \mathrm{U} \\
\text { DAXI } \sim 100 \mathrm{U}\end{array}$ & 36 & 48 \\
\hline $\begin{array}{l}\text { Phase } 2 \text { (Belmont) } \\
\text { (NCT02303002) [32] }\end{array}$ & $\begin{array}{l}\text { Randomized, double-blind, placebo-controlled, } \\
\text { parallel-group, multicenter }\end{array}$ & 9 in Canada & $\begin{array}{l}\text { DAXI } 20 \mathrm{U} \\
\text { DAXI } 40 \mathrm{U} \\
\text { DAXI } 60 \mathrm{U} \\
\text { Onabotuli- } \\
\text { numtoxinA } \\
20 \mathrm{U} \\
\text { Placebo }\end{array}$ & 24 & 286 \\
\hline $\begin{array}{l}\text { Phase } 3 \text { (SAKURA 1) } \\
\text { (NCT03014622) [15, 33] }\end{array}$ & $\begin{array}{l}\text { Randomized, double-blind, placebo-controlled, } \\
\text { parallel-group, multicenter }\end{array}$ & 15 in USA & $\begin{array}{l}\text { DAXI } 40 \mathrm{U} \\
\text { Placebo }\end{array}$ & 36 & 303 \\
\hline $\begin{array}{l}\text { Phase } 3 \text { (SAKURA 2) } \\
\text { (NCT03014635) [15, 33] }\end{array}$ & $\begin{array}{l}\text { Randomized, double-blind, placebo-controlled, } \\
\text { parallel-group, multicenter }\end{array}$ & $\begin{array}{l}6 \text { in Canada } \\
9 \text { in USA }\end{array}$ & $\begin{array}{l}\text { DAXI } 40 \mathrm{U} \\
\text { Placebo }\end{array}$ & 36 & 306 \\
\hline $\begin{array}{l}\text { Phase } 3 \text { (SAKURA 3/OLS) } \\
\text { (NCT03004248) [16, 34] }\end{array}$ & Open-label, multicenter & 65 in USA and Canada & DAXI $40 \mathrm{U}$ & 84 & 2691 \\
\hline
\end{tabular}

$D A X I$ DaxibotulinumtoxinA for Injection, $O L S$ open-label study 
subjects treated with DAXI $60 \mathrm{U}$ and one subject treated with onabotulinumtoxinA $20 \mathrm{U}$. Overall, the DAXI $40 \mathrm{U}$ dose had the most favorable risk:benefit profile [32, 35] and was subsequently evaluated in the Phase 3 pivotal trials.

\subsubsection{Phase 3 Pivotal Trials}

Two identical randomized, double-blind, placebo-controlled, parallel-group, multicenter Phase 3 pivotal trials (SAKURA 1 and SAKURA 2) were conducted to evaluate the efficacy and safety of DAXI $40 \mathrm{U}[15,33]$. In total, 609 adults with moderate or severe glabellar lines at maximum frown were enrolled. All subjects received a single treatment and were followed for up to 36 weeks [15]. In both trials, the proportion of subjects who achieved $\mathrm{a} \geq 2$-point improvement from baseline in glabellar line severity at maximum frown based on both the IGA-FWS and Patient Frown Wrinkle Severity (PFWS) score at Week 4 was significantly higher with DAXI than with placebo at $73.6 \%$ vs $0.0 \%$, respectively, in SAKURA 1 and $74.0 \%$ vs $1.0 \%$, respectively, in SAKURA 2 ( $p<0.0001$ for both) [15]. The proportion of subjects achieving glabellar line severity of none or mild at Week 4 was $97.5 \%$ with DAXI in both trials compared with $\leq 4.9 \%$ with placebo ( $p<0.0001$ for both). Median duration of effect (defined as time over which none or mild glabellar line severity score was maintained) was 24.0 weeks, and median time to return to baseline levels was 27.1 weeks [33].

The safety and tolerability profile of DAXI in the SAKURA trials was similar to that reported in the Phase 2 study $[15,33]$. Treatment-related AEs were primarily mild, with headache and injection site AEs (pain, erythema, and edema) being the most common treatment-related AEs. Eyelid ptosis occurred in $2.2 \%$ of DAXI-treated subjects; all cases resolved without sequelae. No subjects developed neutralizing antibodies to DAXI, assessed using the validated mouse protection assay $[15,33]$.

\subsubsection{Open-Label Safety Study}

SAKURA 3 was an open-label, multicenter Phase 3 trial that evaluated single and repeat treatments of DAXI $40 \mathrm{U}$ for up to 84 weeks $[16,34]$. This study was an extension of the pivotal trials, including substantially more subjects $(n=2691)$ at 65 clinical sites in the USA and Canada. Efficacy outcomes and duration of effect were consistent with those reported in the Phase 2 and Phase 3 pivotal trials. The proportion of subjects who achieved none or mild glabellar line severity at maximum frown over time based on IGA-FWS score was consistent across the Phase 3 studies and after repeated doses, and also showed consistency with the Phase 2 dose-ranging study (Fig. 2). Median duration of effect (time to loss of none or mild glabellar line severity at maximum frown based on both the IGA-FWS and PFWS scores) was 24 weeks, which was remarkably consistent across the Phase 3 studies (Fig. 3), and median time to return to baseline severity on both scales was 28 weeks.

The safety and tolerability profile of DAXI in SAKURA 3 was similar to that reported in the SAKURA 1 and SAKURA 2 trials with no new safety signals [34]. Headache and injection site AEs (pain, erythema, and edema) were the most common treatment-related AEs. These generally resolved within 1-2 days and were mild in severity. The frequency of AEs tended to decrease over subsequent DAXI treatments. No serious AEs were considered related to DAXI treatment. Treatment-related eyelid ptosis occurred with $0.9 \%$ of DAXI treatments; most ptosis events (82.4\%) were mild in severity, and the median time to resolution of eyelid ptosis was 43 days. These rates are comparable to rates reported in prescribing information for onabotulinumtoxinA (3\%), abobotulinumtoxin A ( $2 \%$ ), prabotulinumtoxinA (2\%), and incobotulinumtoxin A $(0.2 \%)[5-7,36]$. No subjects developed neutralizing antibodies to DAXI after exposure to three cycles of treatment [34].
Fig. 2 Consistency in response to DaxibotulinumtoxinA for Injection (DAXI) treatment across Phase 2 and 3 clinical trials. Response was defined as achievement of none or mild glabellar line (GL) severity at maximum frown based on investigator assessment via the validated 4-point Investigator Global Assessment-Frown Wrinkle Severity score (ranging from none [0] to severe [3]). $O L S$ open-label study

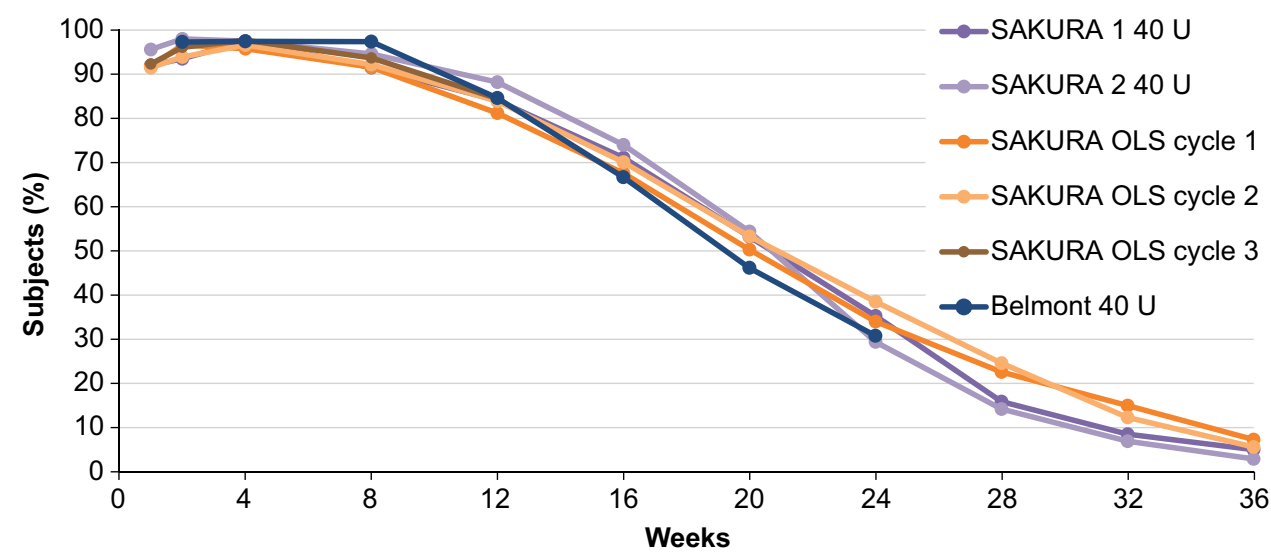


Fig. 3 Consistency in duration of effect (time to loss of none or mild glabellar line severity at maximum frown based on both IGA-FWS and PFWS) following DaxibotulinumtoxinA for Injection (DAXI) treatment in the Phase 3 SAKURA clinical trials. $C I$ confidence interval, $I G A-F W S$ Investigator Global Assessment-Frown Wrinkle Severity, PFWS Patient Frown Wrinkle Severity

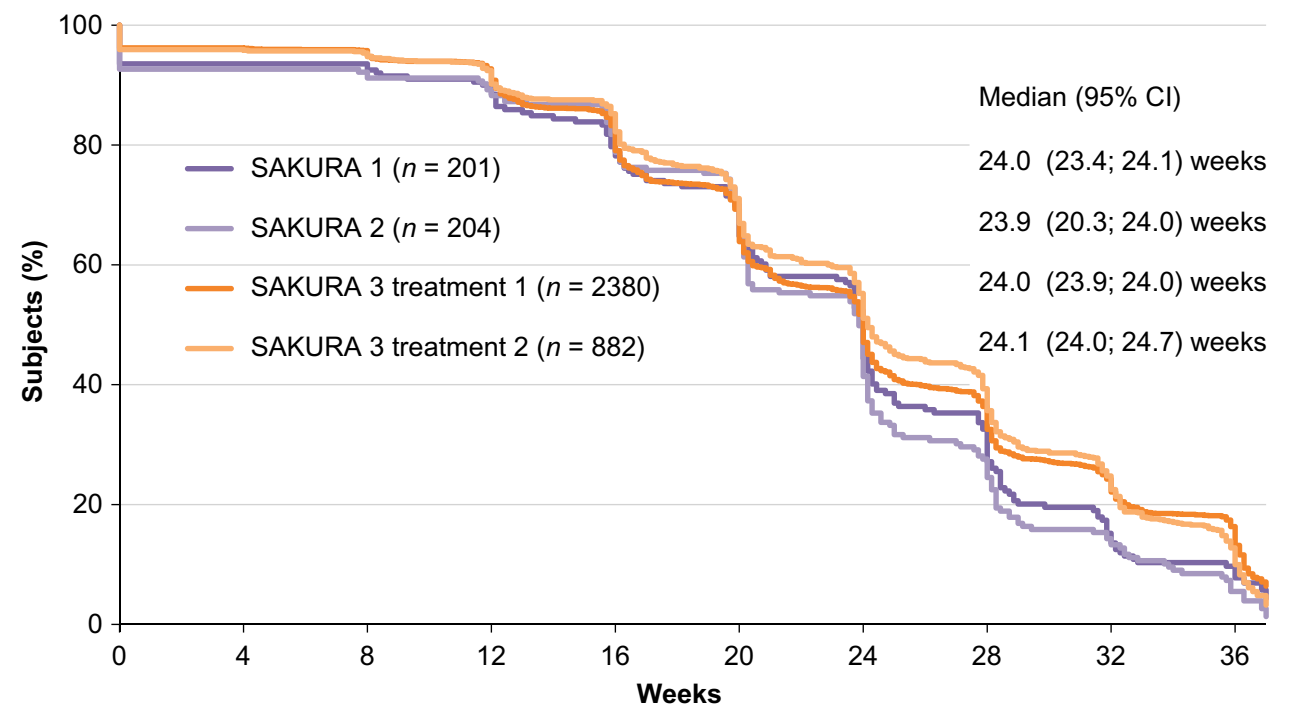

\subsection{Overview of DAXI Cervical Dystonia Clinical Program}

DAXI is being investigated for several therapeutic indications, including the treatment of cervical dystonia. Cervical dystonia, also known as spasmodic torticollis, is a chronic neurological condition resulting in painful and debilitating twisting of the neck and shoulders [37]. BoNTA treatment is currently recommended as first-line therapy for adults with cervical dystonia $[2,38]$, but patients report declining symptom relief at approximately 10-16 weeks after injection with currently approved BoNTAs [8-10, 39-41], necessitating 3-5 treatments per year to manage symptoms, which is a burden on patients and the healthcare system. Furthermore, as many payors do not permit re-treatment before the recommended reinjection interval of at least 12 weeks for cervical dystonia $[5,7,10,40]$, patients must endure periods when their recurring symptoms are not managed. Thus, there is a need for a safe and effective treatment that provides a longer duration of cervical dystonia symptom relief.

\subsubsection{Phase 2 Dose-Ranging Study}

An open-label, dose-escalation, Phase 2 study evaluated the efficacy and safety of three doses of DAXI (200 U, 200-300 U, and $300-450 \mathrm{U}$ ) in adults with moderate-to-severe isolated (primary) cervical dystonia [12]. Overall, 37 subjects were enrolled, received a single DAXI treatment, and were followed for up to 24 weeks. Using the Toronto Western Spasmodic Torticollis Rating Scale (TWSTRS) total score, a measure of cervical dystonia severity, disability, and pain on a scale of 0-85 with higher scores indicating greater impairment [42], mean change from baseline was -16.86 (38\%) at Week 4 (primary endpoint), $-21.3(50 \%)$ at Week 6 , and $-12.8(30 \%)$ at Week 24 across all subjects. The response rate (the proportion of subjects with $\geq 20 \%$ reduction in TWSTRS total score from baseline) was $83 \%$ at Week 4 , $94 \%$ at Week 6, and $68 \%$ at Week 24. Median duration of response was 25.3 weeks [12].

Treatment-related AEs were transient and mild or moderate in severity and no apparent dose response or dose-related increase was observed. The most common treatment-related AEs were dysphagia (14\% of subjects) and injection-site erythema ( $8 \%$ of subjects), and these were unrelated to the dose administered. No serious AEs occurred [12]. No subjects developed neutralizing antibodies in this study [43].

\subsubsection{Phase 3 Program}

The Phase 3 program in adults with cervical dystonia includes a pivotal, randomized, double-blind, placebocontrolled Phase 3 trial (ASPEN-1) and a long-term, openlabel efficacy and safety study (ASPEN-OLS) conducted in Canada, Europe, and the USA [44, 45]. ASPEN-1 $(n=301$ subjects), which was conducted to evaluate the efficacy and safety of two doses of DAXI (125 U or $250 \mathrm{U}$ ), completed in June 2020 [44]. At peak efficacy, averaged over Weeks 4 and 6, least squares mean change from baseline in TWSTRS total score was -12.7 (31\%) with DAXI $125 \mathrm{U}$ and -10.9 (27\%) with DAXI $250 \mathrm{U}$, which was a significantly greater improvement compared with placebo (least squares mean [standard error] difference vs placebo -8.5 [1.93] and -6.6 [1.92], respectively; $p<0.001$ for each dose) [13]. These improvements in TWSTRS total score with DAXI are at least as large as reported with other BoNTAs at Week 4 (incobotulinumtoxinA difference vs placebo -7.5 with $120 \mathrm{U}$ and -9.0 with $240 \mathrm{U}$; abobotulinumtoxinA difference vs placebo -8.9 and -5.9 with $500 \mathrm{U}$ ) $[5,46]$. Median duration of effect, as determined by time to loss of $80 \%$ peak treatment benefit, was 24.0 weeks for DAXI $125 \mathrm{U}$ and 
20.3 weeks for DAXI $250 \mathrm{U}$ (Fig. 4), which is longer than the median effect duration of 12-14 weeks reported with onabotulinumtoxinA, abobotulinumtoxin A, and incobotulinumtoxinA [4, 5, 47]. DAXI was generally safe and well tolerated, with dysphagia reported in $1.6 \%$ of subjects treated with DAXI $125 \mathrm{U}$ and $3.8 \%$ of subjects treated with DAXI $250 \mathrm{U}$ [13]. This is considerably lower than the incidence of dysphagia reported in registration trials of adults with cervical dystonia treated with onabotulinumtoxinA (19\%), abobotulinumtoxinA (15\%), and incobotulinumtoxinA (13-18\%) $[4,5,7]$. The median duration of dysphagia events was 14 days, which is also substantially less than has been reported for other BoNTAs in cervical dystonia [48].

Subjects enrolled in the ASPEN-OLS study $(n=358)$ were eligible for up to four doses of DAXI over 48 weeks [45]. The study completed in May 2021 and data were not available at the time of writing.

\section{Clinical Differentiation of DAXI Versus Currently Available BoNTA Products}

Any comparison between BoNTA products is complicated by the fact that there is no standardized dosing unit for BoNTA products because biological activity is defined by mouse $\mathrm{LD}_{50}$ assay (median lethal dose in mice), and each manufacturer has their own methodology for conducting the $\mathrm{LD}_{50}$ assay as well as their own proprietary reference standard [49]. Therefore, for BoNTAs, units are a relevant measure for comparing dosing for a given toxin product, such as in dose-escalation studies or when comparing the effective doses for aesthetic and therapeutic indications, but regulatory agencies worldwide warn against using units for comparing dosing between different toxin products.

The pharmacological effect of BoNTA is mediated by the core $150-\mathrm{kDa}$ neurotoxin (the active component of all BoNTA products); however, the clinical efficacy will be a function of the amount of active ingredient and the efficiency of delivery of that active ingredient into nerve terminals. The latter is significantly influenced by the formulation.

All currently approved conventional BoNTA products are formulated with HSA as a stabilizer, which prevents loss of activity through protein aggregation and protein adsorption to vial and, potentially, syringe surfaces. These products yield very similar clinical performance at approved doses for cervical dystonia and glabellar lines, with duration in the 3- to 4-month range and similar magnitude of peak efficacy $[4-7,36]$.

DAXI's unique formulation, comprising the RTP004 peptide and other excipients, allows the product to be formulated without HSA and permits a greater functional efficiency to be obtained with the given amount of active core neurotoxin. For example, in the glabellar lines indication, despite a similar mass of core neurotoxin with DAXI $40 \mathrm{U}$ and onabotulinumtoxinA $20 \mathrm{U}$ (each $0.18 \mathrm{ng}$ of core neurotoxin), results from a controlled Phase 2 study demonstrated that DAXI $40 \mathrm{U}$ yielded greater efficacy and duration of effect than onabotulinumtoxinA $20 \mathrm{U}$ with a similar safety profile [32]. Conversely, the mass of core neurotoxin in the $50 \mathrm{U}$ dose of abobotulinumtoxinA ( $0.27 \mathrm{ng}$ of core neurotoxin) yields a clinical efficacy profile in glabellar lines that is generally similar to that of $20 \mathrm{U}$ onabotulinumtoxinA (0.18 $\mathrm{ng}$ of core neurotoxin) (Fig. 5), and a duration of effect of 3-4 months, despite its higher mass of neurotoxin [50]. The higher amount of neurotoxin required for efficacy of
Fig. 4 Median time to loss of $\geq 80 \%$ of peak treatment effect following DaxibotulinumtoxinA for Injection (DAXI) treatment in adults with moderate-tosevere cervical dystonia in the Phase 3 ASPEN-1 trial

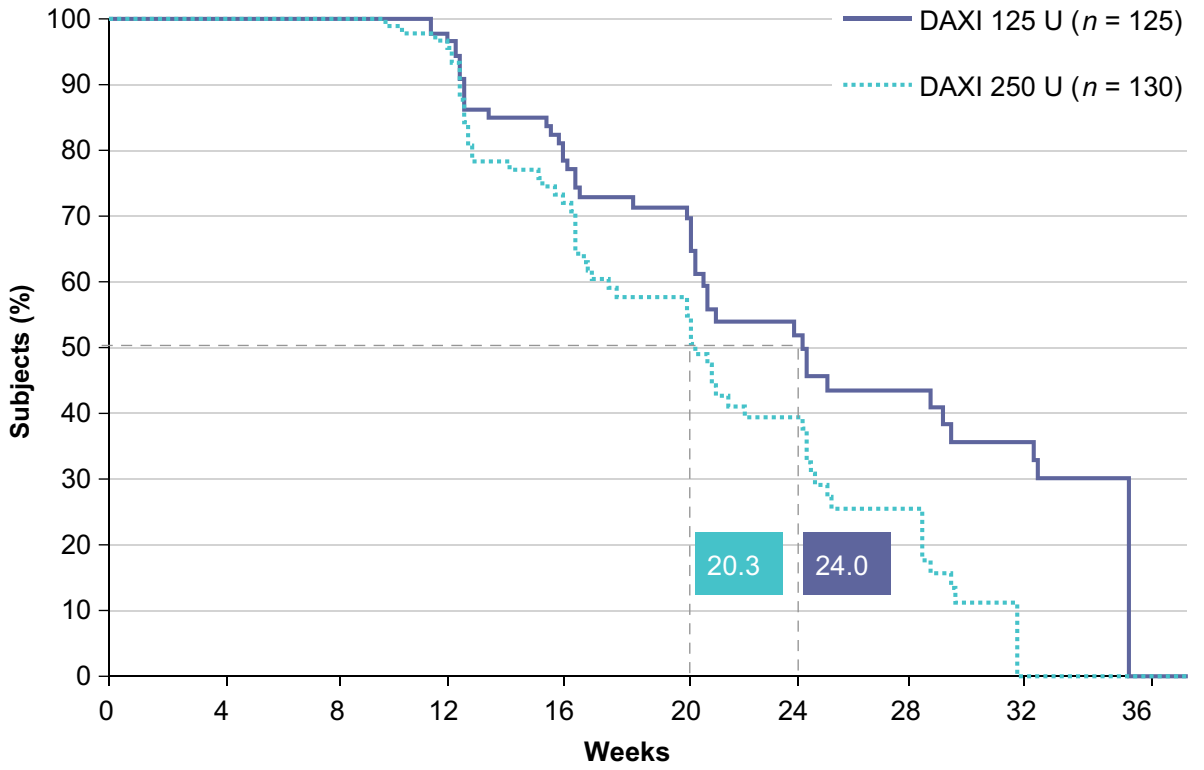




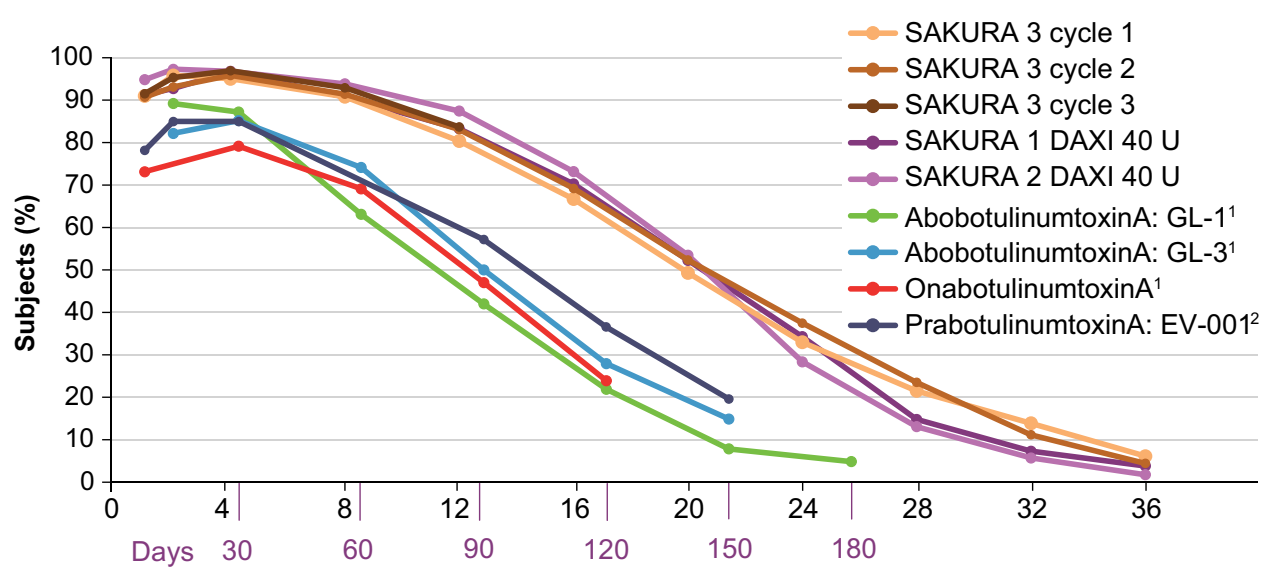

Fig. 5 None or mild response rates for glabellar lines on 4-point investigator assessment over time. This figure presents results from multiple randomized registration studies. Such cross-study comparisons should be interpreted with caution due to potential differences in study design and subject characteristics. ${ }^{1}$ BOTOX ${ }^{\circledR}$ and Dysport ${ }^{\circledR}$ data derived from US Prescribing Information Phase 3 studies in glabellar lines for each neuromodulator with data available through at least Day 120 conducted separately and presented for reference only ${ }^{2}$ Beer et al [54]. DAXI DaxibotulinumtoxinA for Injection

extended duration of effect achieved with a similar or lower amount of core neurotoxin, distinguish DAXI from currently approved BoNTA products.

\section{Declarations}

Funding Neither honoraria nor payments were made for authorship. The open access fee for the manuscript was funded by Revance Therapeutics, Inc. Writing and editorial assistance was provided to the authors by Evidence Scientific Solutions, Philadelphia, PA, and funded by Revance Therapeutics, Inc., Newark, CA.

Conflicts of interest NS, JC, and JK are investigators for Revance Therapeutics, Inc. RGR, TMG, and CJG are employees and stockholders at Revance Therapeutics, Inc.

Ethics approval Not applicable.

Consent to participate Not applicable.

Consent to publish Not applicable.

Availability of data and material Not applicable.

Code availability Not applicable.

Author contributions All authors were involved in the drafting, critical revision, and approval of the final version of the manuscript.

Open Access This article is licensed under a Creative Commons Attribution-NonCommercial 4.0 International License, which permits any non-commercial use, sharing, adaptation, distribution and reproduction in any medium or format, as long as you give appropriate credit to the original author(s) and the source, provide a link to the Creative Commons licence, and indicate if changes were made. The images or other third party material in this article are included in the article's Creative Commons licence, unless indicated otherwise in a credit line to the material. If material is not included in the article's Creative Commons well as the favorable clinical profile, high response rate, and 
licence and your intended use is not permitted by statutory regulation or exceeds the permitted use, you will need to obtain permission directly from the copyright holder. To view a copy of this licence, visit http://creativecommons.org/licenses/by-nc/4.0/.

\section{References}

1. Fonfria E, Maignel J, Lezmi S, Martin V, Splevins A, Shubber S, et al. The expanding therapeutic utility of botulinum neurotoxins. Toxins (Basel). 2018;10(5):208. https://doi.org/10.3390/toxin s10050208.

2. Simpson DM, Hallett M, Ashman EJ, Comella CL, Green MW, Gronseth GS, et al. Practice guideline update summary: botulinum neurotoxin for the treatment of blepharospasm, cervical dystonia, adult spasticity, and headache: report of the Guideline Development Subcommittee of the American Academy of Neurology. Neurology. 2016;86(19):1818-26. https://doi.org/10.1212/ WNL.0000000000002560.

3. Sundaram H, Signorini M, Liew S, Trindade de Almeida AR, Wu Y, Vieira Braz A, et al. Global aesthetics consensus: botulinum toxin type A-evidence-based review, emerging concepts, and consensus recommendations for aesthetic use, including updates on complications. Plast Reconstr Surg. 2016;137(3):518e-e529. https://doi.org/10.1097/01.prs.0000475758.63709.23.

4. Allergan. BOTOX (onabotulinumtoxinA) for injection, for intramuscular, intradetrusor, or intradermal use prescribing information. 2020. https://media.allergan.com/actavis/actavis/media/aller gan-pdf-documents/product-prescribing/20190620-BOTOX-100and-200-Units-v3-0USPI1145-v2-0MG1145.pdf. Accessed 4 Aug 2021.

5. Ipsen. DYSPORT (abobotulinumtoxinA) for injection, for intramuscular use prescribing information. 2018. https://www.ipsen. com/websites/Ipsen_Online/wp-content/uploads/sites/9/2019/01/ 21084019/Dysport_Full_Prescribing_Information.pdf. Accessed 1 Mar 2021.

6. Allergan. BOTOX Cosmetic (onabotulinumtoxinA) for injection, for intramuscular use prescribing information. 2019. https://media. allergan.com/actavis/actavis/media/allergan-pdf-documents/produ ct-prescribing/20190626-BOTOX-Cosmetic-Insert-72715US10Med-Guide-v2-0MG1145.pdf. Accessed 12 Mar 2021.

7. Merz. XEOMIN (incobotulinumtoxinA) for injection, for intramuscular or intraglandular use prescribing information. 2019. https://www.xeominaesthetic.com/wp-content/uploads/2019/05/ XEOMIN-Full-Prescribing-Information-including-MedGuide.pdf. Accessed 12 Mar 2021.

8. Sethi KD, Rodriguez R, Olayinka B. Satisfaction with botulinum toxin treatment: a cross-sectional survey of patients with cervical dystonia. J Med Econ. 2012;15(3):419-23. https://doi.org/10. 3111/13696998.2011.653726.

9. Comella C, Ferreira JJ, Pain E, Azoulai M, Om S. Patient perspectives on the therapeutic profile of botulinum neurotoxin type $\mathrm{A}$ in cervical dystonia. J Neurol. 2020;286(3):903-12. https://doi.org/ 10.1007/s00415-020-10217-7.

10. Poliziani M, Koch M, Liu X. Striving for more good days: patient perspectives on botulinum toxin for the treatment of cervical dystonia. Patient Prefer Adherence. 2016;10:1601-8. https://doi.org/ 10.2147/PPA.S106560.

11. Revance. Data on file.

12. Jankovic J, Truong D, Patel AT, Brashear A, Evatt M, Rubio $\mathrm{RG}$, et al. Injectable daxibotulinumtoxinA in cervical dystonia: a phase 2 dose-escalation multicenter study. Mov Disord Clin Pract. 2018;5(3):273-82. https://doi.org/10.1002/mdc3.12613.

13. Jankovic J, Comella C, Hauser RA, Patel AT, Gross TM, Rubio RG, et al. ASPEN-1. A phase 3 trial evaluating the efficacy, duration of effect, and safety of DaxibotulinumtoxinA for Injection in the treatment of cervical dystonia. Poster presented at: TOXINS 2021; January 16-17, 2021; Virtual.

14. Overman D. DaxibotulinumtoxinA Injection for upper-limb spasticity study receives positive results [press release]. February 24, 2021. https://rehabpub.com/conditions/neurological/stroke-neuro logical/daxibotulinumtoxina-injection-for-upper-limb-spasticitystudy-receives-positive-results/. Accessed 4 Aug 2021.

15. Carruthers JD, Fagien S, Joseph JH, Humphrey SD, Biesman BS, Gallagher CJ, et al. DaxibotulinumtoxinA for Injection for the treatment of glabellar lines: results from each of two multicenter, randomized, double-blind, placebo-controlled, phase 3 studies (SAKURA 1 and SAKURA 2). Plast Reconstr Surg. 2020;145(1):45-58. https://doi.org/10.1097/PRS.0000000000 006327.

16. Fabi SG, Cohen JL, Green LJ, Dhawan S, Kontis TC, Baumann $\mathrm{L}$, et al. DaxibotulinumtoxinA for Injection for the treatment of glabellar lines: efficacy results from SAKURA 3, a large, openlabel, phase 3 safety study. Dermatol Surg. 2021;47(1):48-54. https://doi.org/10.1097/dss.0000000000002531.

17. Solish N, Green JB, Fagien S, Bertucci V, Gallagher CJ, Liu Y, et al. A phase 2a dose-escalation study to evaluate the efficacy and safety of DaxibotulinumtoxinA for Injection for the treatment of dynamic forehead lines following glabellar line injections: an interim analysis. Poster presented at: MauiDerm 2020; January 25-29, 2020; Maui, HI.

18. Stone HF, Zhu Z, Thach TQ, Ruegg CL. Characterization of diffusion and duration of action of a new botulinum toxin type $\mathrm{A}$ formulation. Toxicon. 2011;58(2):159-67. https://doi.org/10.1016/j. toxicon.2011.05.012.

19. Walker TJ, Dayan SH. Comparison and overview of currently available neurotoxins. J Clin Aesthet Dermatol. 2014;7(2):31-9.

20. Malmirchegini R, Too P, Oliyai C, Joshi A. Revance's novel peptide excipient, RTP004, and its role in stabilizing DaxibotulinumtoxinA (DAXI) against aggregation. Poster presented at: TOXINS 2019; January 16-19, 2019; Copenhagen, Denmark.

21. Sebbage V. Cell-penetrating peptides and their therapeutic applications. Biosci Horiz. 2009;2(1):64-72.

22. Ruseska I, Zimmer A. Internalization mechanisms of cell-penetrating peptides. Beilstein J Nanotechnol. 2020;11:101-23. https:// doi.org/10.3762/bjnano.11.10.

23. Vale N, Duarte D, Silva S, Correia AS, Costa B, Gouveia MJ, et al. Cell-penetrating peptides in oncologic pharmacotherapy: a review. Pharmacol Res. 2020;162: 105231. https://doi.org/10. 1016/j.phrs.2020.105231.

24. Kurrikoff K, Vunk B, Langel Ü. Status update in the use of cellpenetrating peptides for the delivery of macromolecular therapeutics. Expert Opin Biol Ther. 2021;21(3):361-70. https://doi.org/ 10.1080/14712598.2021.1823368.

25. Reissmann S, Filatova MP. New generation of cell-penetrating peptides: functionality and potential clinical application. J Pept Sci. 2021;27(5): e3300. https://doi.org/10.1002/psc.3300.

26. Korivi M, Huang YW, Liu BR. Cell-penetrating peptides as a potential drug delivery system for effective treatment of diabetes. Curr Pharm Des. 2020;27(6):816-25. https://doi.org/10.2174/ 1381612826666201019102640.

27. Weisemann J, Rummel A, Oliyai C, Too P, Joshi A. novel peptide excipient RTP004 enhances the binding of botulinum neurotoxin A cell binding domain $\mathrm{Hc}$ to rat brain synaptosomes. Poster presented at: TOXINS 2019; January 16-19, 2019; Copenhagen, Denmark.

28. Yin L, Masuyer G, Zhang S, Zhang J, Miyashita SI, Burgin D, et al. Characterization of a membrane binding loop leads to engineering botulinum neurotoxin B with improved therapeutic efficacy. PLoS Biol. 2020;18(3): e3000618. https://doi.org/10.1371/ journal.pbio.3000618. 
29. Glogau RG, Waugh JM. Preclinical transcutaneous flux experiments using a macromolecule transport system (MTS) peptide for delivery of botulinum toxin type A. Poster presented at: Annual Meeting of the American Academy of Dermatology; February 1-8, 2008; San Antonio, TX.

30. Smyth T, Oliyai C, Joshi A. Stabilizing effect of RTP004 on nonspecific surface adsorption in drug product manufacturing of daxibotulinumtoxinA (DAXI). Poster presented at: TOXINS 2019; January 16-19, 2019; Copenhagen, Denmark.

31. Garcia-Murray E, Velasco Villasenor ML, Acevedo B, Luna S, Lee J, Waugh JM, et al. Safety and efficacy of RT002, an injectable botulinum toxin type A, for treating glabellar lines: results of a phase $1 / 2$, open-label, sequential dose-escalation study. Dermatol Surg. 2015;41(Suppl 1):S47-55. https://doi.org/10.1097/DSS. 0000000000000276.

32. Carruthers J, Solish N, Humphrey S, Rosen N, Muhn C, Bertucci $\mathrm{V}$, et al. Injectable DaxibotulinumtoxinA for the treatment of glabellar lines: a phase 2, randomized, dose-ranging, double-blind, multicenter comparison with onabotulinumtoxinA and placebo. Dermatol Surg. 2017;43(11):1321-31. https://doi.org/10.1097/ DSS.0000000000001206.

33. Bertucci V, Solish N, Kaufman-Janette J, Yoelin S, Shamban A, Schlessinger J, et al. DaxibotulinumtoxinA for Injection has a prolonged duration of response in the treatment of glabellar lines: Pooled data from two multicenter, randomized, double-blind, placebo-controlled, phase 3 studies (SAKURA 1 and SAKURA 2). J Am Acad Dermatol. 2020;82(4):838-45. https://doi.org/10. 1016/j.jaad.2019.06.1313.

34. Green JB, Mariwalla K, Coleman K, Ablon G, Weinkle SH, Gallagher CJ, et al. A large, open-label, phase 3 safety study of DaxibotulinumtoxinA for Injection in glabellar lines: a focus on safety from the SAKURA 3 study. Dermatol Surg. 2021;47(1):42-6. https://doi.org/10.1097/dss.0000000000002463.

35. Bertucci V, Humphrey S, Carruthers J, Solish N, Muhn C, Swift A, et al. Comparing injectable daxibotulinumtoxinA and onabotulinumtoxinA in moderate and severe glabellar lines: additional analyses from a phase 2, randomized, dose-ranging, double-blind, multicenter study. Dermatol Surg. 2017;43:S262-73. https://doi. org/10.1097/DSS.0000000000001364.

36. Evolus. JEUVEAU (prabotulinumtoxinA-xvfs) for injection, for intramuscular use prescribing information. 2020. https://info.evolus.com/hubfs/Prescribing\%20Info_20200130.pdf. Accessed 12 Mar 2021.

37. Dystonia Medical Research Foundation. Cervical dystonia. https:// dystonia-foundation.org/what-is-dystonia/types-dystonia/cervicaldystonia/. Accessed 14 Mar 2021.

38. Contarino MF, Van Den Dool J, Balash Y, Bhatia K, Giladi N, Koelman JH, et al. Clinical practice: evidence-based recommendations for the treatment of cervical dystonia with botulinum toxin. Front Neurol. 2017;8:35. https://doi.org/10.3389/fneur. 2017.00035.

39. Marsh WA, Monroe DM, Brin MF, Gallagher CJ. Systematic review and meta-analysis of the duration of clinical effect of onabotulinumtoxinA in cervical dystonia. BMC Neurol. 2014;14:91. https://doi.org/10.1186/1471-2377-14-91.

40. Evidente VG, Pappert EJ. Botulinum toxin therapy for cervical dystonia: the science of dosing. Tremor Other Hyperkinet Mov (N Y). 2014;4:273. https://doi.org/10.7916/D84X56BF.

41. Dressler D, Tacik P, Saberi FA. Botulinum toxin therapy of cervical dystonia: duration of therapeutic effects. J Neural Transm (Vienna). 2015;122(2):297-300. https://doi.org/10.1007/ s00702-014-1253-8.

42. Consky E, Lang A. Clinical assessments of patients with cervical dystonia. In: Jankovic J, Hallett M, editors. Therapy with botulinum toxin. New York: Marcel Dekker; 1994. p. 211-37.
43. Brashear A, Truong D, Comella C, Jankovic J, Patel A, Prawdzik $\mathrm{G}$, et al. DaxibotulinumtoxinA for Injection in adults with cervical dystonia from a phase 2 dose-escalation multicenter study. Poster presented at: American Academy of Neurology 2019, May 4-10, 2019; Philadelphia, PA.

44. ClinicalTrials.gov. Single treatment of DaxibotulinumtoxinA for Injection in adults with isolated cervical dystonia (ASPEN-1). https://clinicaltrials.gov/ct2/show/NCT03608397?term=cervi $\mathrm{cal}+$ dystonia\& cond $=$ daxibotulinumtoxin $\mathrm{A} \& \mathrm{draw}=2 \& \mathrm{rank}=1$. Accessed 30 July 2020.

45. ClinicalTrials.gov. Long-term safety and efficacy of repeat treatments of DaxibotulinumtoxinA for Injection in adults with isolated cervical dystonia (ASPEN-OLS). https://clinicaltrials.gov/ ct2/show/NCT03617367?term=DaxibotulinumtoxinA\&cond= Cervical + Dystonia $\&$ phase $=2 \&$ fund $=2 \&$ draw $=2 \&$ rank $=1$. Accessed 19 Nov 2020.

46. Comella CL, Jankovic J, Truong DD, Hanschmann A, Grafe S, US XEOMIN Cervical Dystonia Study Group. Efficacy and safety of incobotulinumtoxinA (NT 201, XEOMIN®, botulinum neurotoxin type $\mathrm{A}$, without accessory proteins) in patients with cervical dystonia. J Neurol Sci. 2011;308(1-2):103-9. https://doi.org/10. 1016/j.jns.2011.05.041.

47. Comella CL, Jankovic J, Shannon KM, Tsui J, Swenson M, Leurgans $\mathrm{S}$, et al. Comparison of botulinum toxin serotypes $\mathrm{A}$ and $\mathrm{B}$ for the treatment of cervical dystonia. Neurology. 2005;65(9):1423-9. https://doi.org/10.1212/01.wnl.0000183055. $81056.5 \mathrm{c}$.

48. Naumann M, Yakovleff A, Durif F, BOTOX Cervical Dystonia Prospective Study Group. A randomized, double-masked, crossover comparison of the efficacy and safety of botulinum toxin type A produced from the original bulk toxin source and current bulk toxin source for the treatment of cervical dystonia. J Neurol. 2002;249(1):57-63. https://doi.org/10.1007/p100007848.

49. Frevert J. Content of botulinum neurotoxin in Botox ${ }^{\circledR} /$ Vistabel ${ }^{\circledR}$, Dysport ${ }^{\circledR} /$ Azzalure ${ }^{\circledR}$, and Xeomin ${ }^{\circledR} /$ Bocouture ${ }^{\circledR}$. Drugs R D. 2010;10(2):67-73. https://doi.org/10.2165/11584780-00000 0000-00000.

50. U. S. Food and Drug Administration. Center for Drug Evaluation and Research. Medical review: Dysport - abobotulinumtoxin A. 2009. https://www.accessdata.fda.gov/drugsatfda_docs/nda/2009/ 125274Orig1s001MedR.pdf. Accessed 25 Feb 2021.

51. Bigalke H, Wohlfarth K, Irmer A, Dengler R. Botulinum A toxin: dysport improvement of biological availability. Exp Neurol. 2001;168(1):162-70. https://doi.org/10.1006/exnr.2000.7583.

52. Mohammadi B, Kollewe K, Wegener M, Bigalke H, Dengler R. Experience with long-term treatment with albumin-supplemented botulinum toxin type A. J Neural Transm (Vienna). 2009;116(4):437-41. https://doi.org/10.1007/s00702-009-0200-6.

53. Field M, Splevins A, Picaut $P$, van der Schans M, Langenberg $\mathrm{J}$, Noort D, et al. AbobotulinumtoxinA (Dysport ${ }^{\circledR}$ ), Onabotulinumtoxin $A\left(\right.$ Botox $\left.^{\circledR}\right)$, and IncobotulinumtoxinA $\left(\right.$ Xeomin $\left.^{\circledR}\right)$ neurotoxin content and potential implications for duration of response in patients. Toxins (Basel). 2018;10(12):535. https://doi.org/10. 3390/toxins 10120535.

54. Beer KR, Shamban AT, Avelar RL, Gross JE, Jonker A. Efficacy and safety of prabotulinumtoxinA for the treatment of glabellar lines in adult subjects: results from 2 identical phase III studies. Dermatol Surg. 2019;45(11):1381-93. https://doi.org/10.1097/ dss.0000000000001903. 